Volume 5(3), 60-72. http://dx.doi.org/10.18608/jla.2018.53.5

\title{
Taken Together: Conceptualizing Students' Concurrent Course Enrollment across the Post- Secondary Curriculum Using Temporal Analytics
}

\author{
Michael Brown ${ }^{1}$, R. Matthew DeMonbrun², Stephanie Teasley ${ }^{3}$
}

\begin{abstract}
In this study, we develop and test four measures for conceptualizing the potential impact of co-enrollment in different courses on students' changing risk for academic difficulty and recovery from academic difficulty in a focal course. We offer four predictors, two related to instructional complexity and two related to structural complexity (the organization of the curriculum) that highlight different trends in student experience of the focal course. Course difficulty, discipline of major, time in semester, and simultaneous difficulty across courses were all significantly related to entering a moderate and high-risk classification in the early warning system (EWS). Course difficulty, discipline of major, and time in semester were related to exiting academic difficulty classifications. We observe a snowball effect, whereby students who are experiencing difficulty in the focal course are at increased risk of experiencing difficulty in their other courses. Our findings suggest that different metrics may be needed to identify risk for academic difficulty and recovery from academic difficulty. Our results demonstrate what a more holistic assessment of academic functioning might look like in early warning systems and course recommender systems, and suggest that academic planners consider the relationship between course co-enrollment and student academic success.

\section{Notes for Practice}

- Research on academic performance typically focuses on single course outcomes, but students who are most at risk could be experiencing difficulty in more than one course during an academic term.

- This paper demonstrates how data from early warning systems can be utilized to characterize student performance throughout the term, allowing investigation of how and when students experience academic difficulty and recovery across co-enrolled courses.

- We identify three consistent significant influences on changing odds of risk of academic difficulty: 1) whether a student is concurrently enrolled in another difficult course as defined by historical early warning system data, 2) a student's academic major, and 3) a snowball effect whereby increased risk in the focal course is linked to increased risk of academic difficulty in other coursework.

- Utilizing the methods presented in this paper on data from their own institution, practitioners could reflect on the organization of their system-wide curriculum to best support student academic planning. For example, practitioners could use these measures to identify high risk courses for intervention or enhance the development of early warning and course recommender systems by integrating more holistic measures of student success.
\end{abstract}

\section{Keywords}

Educational technology, curriculum analytics, survival analysis, early warning systems, undergraduate education.

Submitted: 06.08.2018 - Accepted: 30.08.2018 — Published: 11.12.2018

Corresponding author ${ }^{1}$ Email: brownm@iastate.edu Address: School of Education, College of Human Sciences, lowa State University.2466B Lagomarcino Hall, 901 Stange Road, 50010, Ames, IA, USA ORCID: 0000-0002-2561-7037

${ }^{2}$ Email: mdemonbr@umich.edu Address: Center for the Study of Higher and Postsecondary Education, University of Michigan, 610 E. University Ave., Room 2117, 48109-1259, Ann Arbor, MI, ORCID: 0000-0002-1742-9984

3Email: steasley@umich.edu, School of Information, 105 S. State St., 48109, Ann Arbor, MI., USA 


\section{Introduction}

Considerable attention has been paid to students as they experience academic difficulty in higher education (Pascarella \& Terenzini, 2005). Institutions in North America invest in tutoring resources, supplemental instruction, summer transition programs, and instructional technology in an effort to promote student success in the classroom (Chambliss \& Takacs, 2014). Many investigations into undergraduate academic difficulty focus on students in a single identified course. Yet, the students who are the most at risk may in all likelihood be experiencing difficulty across the curriculum. Student persistence is not exclusively a function of their performance in an individual course.

Instead, students build momentum as they navigate the curriculum, and that momentum may have a gravitational effect of its own, directing students through curricular requirements that constitute majors, minors, and certificates. Students' early course taking and enrollment behaviour can set a trajectory for their future coursework (Attewell, Heil, \& Reisel, 2012). There may be an "additive effect" of credit accrual to academic achievement over time for undergraduate students, an influence that appears to be stronger than prior academic preparation (Martin, Wilson, Liem, \& Ginns, 2013). As such, advisors may encourage students to increase their academic load in order to ensure that they maintain momentum towards degree requirements. Students may also be more likely to choose courses that offer clear pathways towards degree attainment, delaying courses so as not to take too many concurrent difficult courses (and risk their momentum). The pathways to credit accrual and degree attainment are not frictionless (Slim, 2016).

It may be that institutions unintentionally create roadblocks to momentum when they organize academic program requirements in ways that complicate student pathways to the degree (Slim, Kozlick, Heileman, \& Abdallah, 2014d; Wigdahl, Heileman, Slim, \& Abdallah, 2014). The organizational pathways carved out by complex curricular requirements may be one reason some trajectories towards completing degree requirements are more popular than others (Dawson \& Hubball, 2014). Such an approach can include stopping out of introductory science, technology, engineering, and math course sequences and focusing on courses where they perceive a greater likelihood of attaining academic success (Seymour \& Hewitt, 1997). Although students are provided the latitude to navigate the curriculum, some arrangements of coursework might simply be too cumbersome. Pathways where students perceived substantial opportunity costs (for example, courses that require a disproportionate amount of a student's time) may blunt students' achievement motivation (Eccles \& Wigfield, 2002), especially in science, technology, engineering, and math (STEM) fields (Perez, Cromley, \& Kaplan, 2014). Identifying these roadblocks in the curriculum, and either removing them or providing sufficient support to help students navigate them is an important policy objective for institutions interested in promoting persistence.

\section{Literature Review}

Examining student pathways through the curriculum have, historically, proven difficult for researchers who were interested in academic events within the context of a semester. Instead, studies of the curriculum required a semester long view (Ishitani, 2006). More fine-grained data about student experiences in the curriculum, such as weekly activity and performance metrics, were often unavailable, especially at a scale that would allow for the analysis of multiple courses concurrently. The advent of early warning systems provides researchers with an opportunity to look at how students perform across the curriculum over time (Macfadyen \& Dawson, 2010). Specifically, scholars might be better able to identify patterns of difficulty - in certain courses, certain disciplines, or certain course combinations - that merit specific intervention to help students recover academically.

The increased collection of temporal learning analytics data about post-secondary students (Knight, Wise \& Chen, 2017) has resulted in a number of investigations that explore how students perform and self-regulate in their coursework over time (e.g., Brown, DeMonbrun, Lonn, Aguilar, \& Teasley, 2016; Brown, DeMonbrun, \& Teasley, 2017). Through that work, researchers have identified that the organization of the curriculum and the timing of events in the curriculum can impact student success (Brown et al., 2017; Slim, Heileman, Kozlick, \& Abdallah, 2014a). Undergraduate students typically register for multiple courses in a single term selected from a university's offering of hundreds of classes.

Students have different objectives in mind when they select a course. However, some objectives are common. First, students need to complete general education requirements, which usually involve a broad spectrum of introductory courses across disciplines, and students aim to make progression through coursework towards degree attainment. These objectives encourage students to take required courses early (especially if those courses are pre-cursors to major requirements or to declaring a major) and to take a specific number of courses in a semester (Wang, Liu, \& Chen, 2017). Students are engaged in multiple concurrent academic tasks, over time, with competing goals, aspirations, and requirements (Tinto, 1997). Performance in one course does not happen in isolation. Therefore, what happens in course A might be influenced by the difficulty (or ease) experienced in course B (and course C, D, etc.; Slim, Heileman, Kozlick, \& Abdallah, 2014b).

Much of the literature on undergraduate persistence in North American higher education focuses on within-college effects (Mayhew et al., 2016). This includes a host of institutional factors like quality of instruction, programmatic interventions, financial aid, and the campus environment (Pascarella \& Terenzini, 2005). What is left largely unaddressed in the literature on 
institutional factors is the question of the design and organization of the curriculum (Nespor, 2007). The common approach in research on post-secondary education is to treat curriculum as content, when in reality curricula constitute a complex network of interdependencies (Nespor, 2007). In this way, the undergraduate curriculum is more like a trajectory that students need to navigate both within and across academic terms. Instructional and assessment events are temporally ordered throughout the term for each individual course, but students experience many of their academic tasks concurrently through enrollment in multiple courses, resulting in tasks that coincide and abut each other. Examining student performance as if each course were taken in isolation obscures the potential impact of course combinations. In fact, particular combinations of courses taken within the same term can be academically hazardous to individual students (Nam, Lonn, Brown, Davis, \& Koch, 2014).

As part of the expanding literature on learning analytics, temporal analytics have been utilized for modelling student experiences in the curriculum (see Mahzoon, Maher, Eltayeby, Dou, \& Grace, 2018 for a discussion). For example, Hodara and Rodríguez (2013) developed an analytical model to explore student progression through a core curriculum in a community college system. They observed that students with lower levels of progression through the core curriculum were unlikely either to complete an associate's degree program successfully or to transfer to a bachelor's degree program successfully. Dawson and Hubball (2014) outlined an approach to curriculum analytics where courses are connected through directed network graphs, identifying the most common pathways students take to completing a degree. Researchers at the University of New Mexico developed a similar approach to identify curricular efficiency, identifying how a student might move through a curriculum given the frequency of course offerings (Slim et al., 2014b; Slim, Kozlick, Heileman, Wigdahl, \& Abdallah, 2014c; Wigdahl, Heileman, Slim, \& Abdallah, 2014).

The majority of curricular analytics research focuses on students' course-taking behaviour and their degree progression (e.g., Dawson \& Hubball, 2014; Lightfoot, 2010; Meghanathan, 2017; Villano, Harrison, Lynch, \& Chen, 2018). Our work builds on this foundation to explore curricular complexity through its two primary components: structural complexity and instructional complexity (Heileman, Hickman, Slim, \& Abdallah, 2017). Structural complexity encompasses the order, organization, and interdependence of courses in a curriculum. Instructional complexity involves the inherent difficulty of the courses in a curriculum, the quality and nature of instruction, and the availability of academic support (among other factors). Improving structural complexity could yield curricular pathways that promote time to degree. Identifying courses (or course combinations) that involve significant academic challenge (instructional complexity) could help administrators, instructors, and academic planners direct academic support resources.

A number of scholars have outlined some promising approaches to curricular temporal analytics, largely focused on addressing structural inequality in the curriculum. Much of this work uses network graphs to identify interdependencies within the curriculum that result in complex organizational structures (e.g., Meghanathan, 2017; Phadke \& Kulkarni, 2018; Willcox \& Huang, 2017). In addition to Dawson and Hubball's (2014) work, contextual graphs have been applied to predict future enrollment patterns and student course preferences at one institution (Wang et al., 2017). Using course-taking data from the Beyond Post-Secondary Survey, Wang (2016) identified the need for a robust pathway to transfer into 4-year institutions for Community College STEM students. Using a similar complex graph approach, Aldrich (2015) developed analytic tools for identifying a curricular prerequisite network. Focused on structural complexity, this work builds on prior transcript analysis that shaped institutional and public policy (Adelman, 2006; Calcagno, Crosta, Bailey, \& Jenkins, 2006). We found no examples of temporal analytics research that combined measures of instructional and structural complexity in the curriculum.

In order to leverage temporal data about behaviour and performance we need to conceptualize concurrent enrollment for the purpose of modelling and explaining student experiences with academic difficulty and their recovery efforts. In a large lecture course where students are each taking three to five classes concurrently, there may be hundreds of additional courses that need to be accounted for, especially if we are interested in the way that academic difficulty might spread through a student's coursework.

\section{Guiding Research Questions}

The previous research outlined above mostly focuses on end-of-semester outcomes like the student's final grade or whether they received course credit. While a semester-to-semester view on student success can offer important implications, an advantage of learning analytics data is that researchers can view changes in student performance at a more granular level. For example, in two prior studies the authors found that 1) the timing of assessments may influence student ability to be successful in a course, where students who are struggling in the last third of a semester may have passed a point of no return in science, math, and engineering courses (Brown et al., 2016), and 2) students appear to adopt study strategies early in a course that have implications for their ability to recover from academic difficulty; such that students who fail to adopt some study strategies appear at greater risk for long-term academic difficulty (Brown et al., 2017).

Building on the prior literature on academic momentum and curriculum analytics, in this paper we ask what curricular factors might be significantly related to an increase in a student's odds of experiencing academic difficulty, as a way to conceptualize co-enrollment. For the analysis presented here, we selected a high-stakes STEM-related course as a focal course 
and then examined students' concurrent enrollment in other courses (in addition to the focal course). We investigated the following research questions:

RQ1: What aspects of instructional complexity in the curriculum are significantly related to changes in a student's odds of experiencing academic difficulty?

A. Is concentration in academic coursework, as defined by majoring in a disciplinary field, significantly related to a student's increased odds of experiencing academic difficulty in a focal course?

B. Is co-enrollment in other difficult courses (as defined by the proportion of students in the course who experienced academic difficulty) significantly related to a student's increased odds of experiencing academic difficulty?

RQ2: What aspects of structural complexity in the curriculum are significantly related to changes in a student's odds of experiencing academic difficulty?

A. As time progresses over the semester, do a student's odds of experiencing academic difficulty in the focal course increase?

B. Is co-enrollment in other courses where a student experiences academic difficulty related to increased odds of academic difficulty in the focal course? Do odds of academic difficulty increase with the number of co-enrolled courses in which a student experiences academic difficulty?

RQ3: What aspects of instructional and structural complexity are significantly related to changes in a student's odds of recovery from academic difficulty?

Our prior work detailed the challenges inherent in the instructional complexity of a course. Other scholars have outlined some significant challenges presented by the structures that emerge through the organization of the curriculum. In this study, we demonstrate a number of metrics to examine both instructional and structural complexity in course-taking in an effort to offer some analytical approaches that can be used to enrich data-driven academic planning, early warning systems, and recommender systems. The metrics we develop are based on a few specific propositions drawn from prior research:

1. First, we expect that students concentrating in science, technology, engineering, and mathematics major programs courses should have lower odds of academic difficulty in STEM courses than students majoring in non-STEM fields (Brown, DeMonbrun, \& Teasley, 2018; Feng, Fiorini, Shepard, \& Groth, 2017).

2. Second, we expect that students co-enrolled in multiple difficult courses should have higher odds of poor academic performance over time (e.g., Slim, 2016; Slim et al., 2014c).

3. Third, we expect that as time progresses, students' odds of academic difficulty should increase and their odds of academic recovery will decrease (Brown et al., 2016).

4. Finally, we hypothesize that academic difficulty has a potential snowball effect: as the number of courses in which a student experiences academic difficulty increases, so should their odds of academic difficulty in the course that provides the analytical sample (DeMonbrun, Brown, \& Teasley, 2018). We describe the operationalization of these propositions in the methodology section.

By investigating students' trajectories through the curriculum, we can start to make inferences about the structure of the curriculum (Nespor, 2007). A more accurate characterization of co-enrollment as pathways with greater ease or difficulty has implications for our understanding of undergraduate completion, as well as the design and development of early warning and course recommender systems. In this study, we explore four approaches for conceptualizing concurrent coursework in order to develop analytical methods for exploring student experiences across the curriculum. We describe the strengths and limitations of each approach and offer future directions for the development of conceptual mechanisms for curriculum analytic and temporal learning analytic investigations.

\section{Methodology}

\subsection{Sample}

Students in our sample were enrolled in an introductory programming course (the focal course) in the Electrical Engineering and Computer Science program at a 4-year residential research university in the USA. This course is a prerequisite for many computer science and computer engineering students, while also serving a substantial non-major population at the institution. Our sample includes 987 students who took this course in the Fall 2016 academic term. The course involved lectures twice a week and a weekly lab section. Although taught by three instructors, all instructors used the same instructional resources, including assignments and exams. Students in the sample were $38 \%$ women, and predominantly white (44\%) or Asian (38\%). Most students were in their first (33\%) or second (36\%) year of post-secondary education. 


\subsection{Early Warning System (EWS)}

The university's EWS (Lonn \& Teasley, 2014) gives a weekly categorization of each student's standing within each course with a designation of performance as "ENCOURAGE" (alert status = green: student performing at or above the course mean), "EXPLORE" (alert status = yellow: students performing below the course mean), or "ENGAGE" (alert status = red: students in the lowest quartile of performance), based on various metrics including currently available grade data, student interaction with course tools and materials, and student performance when compared to their peers in the course.

For our analysis, the dependent variable is a dichotomous variable measuring the change in a student's classifications each week $(1=$ change in classification; $0=$ no change in classification). All students begin the semester in the green classification. If a student's alert status changes from green to yellow in the third week of the semester, she is flagged as entering the yellow classification - showing declining performance for that week (i.e., the dependent variable would be flagged as " 1 " instead of "0"). Similarly, students with an alert status changing from green or yellow to red would be flagged as entering the red classification. We also created dependent variables for showing improved performance - exiting out of either the yellow or red classifications. Students must have entered the classification in order to exit it, and once students enter the classification, the exit models indicate how many weeks it takes before the student exits the classification.

We also used data from the EWS to construct the course difficulty measure and the snowball effect measure. For the course difficulty measure, we examined the array of classes in which students in the focal course were also enrolled using data from the EWS. In the vast majority of these classes, fewer than $25 \%$ of students experienced an EXPLORE classification during the term and fewer than 10\% experienced an ENGAGE classification. Therefore, any course that exceeded those thresholds was classified as difficult. Seventy-one classes out of 803 courses in total (9\%) were identified as difficult for the purpose of these analyses. The course difficulty measure is a binary indicator for whether or not an individual student was enrolled in at least one difficult course concurrent to the focal course. For the snowball effect measure, we included covariates to measure the risk of a student with a previous classification (i.e., had an EXPLORE or ENGAGE classification in one course) experiencing similar difficulties in another course concurrently. For example, if a student already had an EXPLORE classification in one course in a given week, we included a covariate for the risk of that same student experiencing an EXPLORE classification in another course during that week (two courses total). Then, for that student's next week in the course, we included a covariate for the risk of experiencing a third EXPLORE classification. No student in our sample experienced more than three EXPLORE or ENGAGE classifications during the semester. These covariates allow us to estimate how students with one or more classifications experience risk patterns differently than students who are experiencing their first classification.

\subsection{Independent Variables}

In this study, we explore four ways of conceptualizing co-enrollment as predictors of academic performance across the term (see Table 1 for all independent variables). Our goal in developing these controls was to create metrics that have strong face validity and would be easily translatable across contexts (both nation-state systems of higher education and potentially among levels within a system). Our first proposition stated that "we expect that students concentrating in science, technology, engineering, and mathematics major programs courses should have lower odds of academic difficulty in STEM courses than students who are not" (Brown et al., 2016; Feng et al., 2017). This is based on prior research that classified undergraduate coursework using Biglan's (1973) typology of disciplines to identify different risk ratios within an early warning system. This typology of disciplinary fields in higher education draws its classification from 1) how each field views disciplinary knowledge, 2) how disciplinary knowledge is used, and 3) what the expectations are for faculty work. Biglan (1973) classified fields across three dimensions: hard/soft, pure/applied, and life/non-life. The hard/soft and pure/applied distinction have been used by a number of researchers to illustrate important disciplinary differences in the student experience of teaching and learning (e.g., Braxton \& Hargens, 1996; Trowler \& Cooper, 2002).

The hard/soft distinction indicates the extent to which there is consensus in a disciplinary field regarding theories, methods, and core problems. In undergraduate education, hard fields like the natural sciences, mathematics, and engineering have a broader field level consensus, in contrast to soft fields like fine arts and the humanities. In a study of undergraduate teaching in North American higher education, Lattuca and Stark (2011) reported that students in hard-field courses spent their time on the acquisition of disciplinary facts, principles, and concepts. Students in soft fields spent more instructional time on activities that developed critical thinking skills. Soft-field instructors spent more time highlighting controversies within the field. Similarly, deep approaches to learning, where integration, synthesis, and reflection are emphasized, are more common in soft fields (Laird \& Garver, 2010).

A similar distinction exists among pure and applied fields. Courses in pure fields spent more time on deep approaches to learning when compared to applied fields (Laird \& Garver, 2010). The distinction between pure and applied fields encompasses how knowledge is constructed within the field. Is scholarship focused on knowledge production (pure) or application of knowledge (applied; Trowler \& Cooper, 2002)? For example, Physics and Mechanical Engineering may be concerned with similar phenomena in undergraduate education, but they approach the development and use of knowledge about that phenomena in different ways. Pure fields expect a higher level of abstraction and theorization to understand course content (Braxton \& Hargens, 1996). Using that research as a guide, we grouped students by major into Biglan's (1973) four typologies 
soft pure, soft applied, hard pure, and hard applied students. We also added a fifth classification for students who had not yet declared a major.

Our second proposition stated that we expected that students co-enrolled in other difficult courses should have higher odds of academic difficulty over time in the focal course (e.g., Slim, 2016; Slim et al., 2014c). To test this proposition, we used the course difficulty measure described in section 4.2 on data from the EWS system.

In our third proposition, we suggested that as time progresses, students' odds of academic difficulty should increase and their odds of academic recovery will decrease (Brown et al., 2017). To account for the influence of time on academic performance, we include three covariates: a linear, squared, and cubed term for temporal progression.

Finally, we proposed that academic difficulty has a potential snowball effect: as the number of courses in which a student experiences academic difficulty increases, so should their odds of academic difficulty across their coursework (DeMonbrun et al., 2018). We used the snowball effect measure described in section 4.2 to test this proposition.

Each of these conceptual measures were included in the academic difficulty and academic recovery models (covered in detail in the next section). We also included several demographic characteristics (e.g., gender, race, international status, and first-year students).

\subsection{Data Analysis}

We used event history modelling (survival analysis) to measure the probability that a student might enter into or exit out of an ENGAGE or EXPLORE alert status given the independent variables listed above. Given the non-continuous nature of graded assessments, we opted to use a discrete-time hazard model in this analysis.

In order to create this type of model, the data must be restructured to capture a sequence of binary responses ( $\mathrm{y}_{\mathrm{ti}}$ ), where the outcome represents whether the event occurred $(1=$ yes; $0=$ no) during sequential time periods $(t)$ for each individual (i). In doing so, we created an observation for each time interval that an individual student received a classification (alert status $=$ ENGAGE or EXPLORE) and was therefore included in the model (i.e., until they either experienced the event or the data collection stopped). The probability ( $\mathrm{p}_{\mathrm{t}}$ ) is estimated for each individual (i) to experience the event during each time interval $(\mathrm{t})$, given that no event has occurred prior to the start of $t$ :

$$
\mathrm{p}_{\mathrm{ti}}=\operatorname{Pr}\left(\mathrm{y}_{\mathrm{ti}}=1 \mid \mathrm{y}_{\mathrm{t}-1, \mathrm{i}}=0\right)
$$

In this equation, $\mathrm{p}_{\mathrm{ti}}$ is called the discrete-time hazard function because it represents the probability of the individual receiving a classification (or exiting that classification) during a specific time period. After computing the probabilities for each individual's time hazard, the data is fit to a binary response model (i.e., logistic regression model):

$$
\log \left(\mathrm{p}_{\mathrm{ti}} / 1-\mathrm{p}_{\mathrm{ti}}\right)=\alpha \mathrm{D}_{\mathrm{ti}}+\beta \mathrm{X}_{\mathrm{ti}}
$$

In this model, $\mathrm{p}_{\mathrm{ti}}$ represents the probability of the event during the time interval $\mathrm{t}, \mathrm{D}_{\mathrm{ti}}$ is a vector of functions representing the total cumulative hazard during the duration by interval $t$ with coefficients $(\alpha)$, and $x_{t i}$ is a vector of covariates with coefficients $(\beta)$. Each individual receives a baseline hazard function (represented by $\mathrm{D}_{\mathrm{ti}}$ ), while the covariates can either increase or decrease the hazard function for each individual. The results of the logistic regression model are given in terms of $\log$ odds for ease of discussion. In total, four models were estimated for our analysis. We also included multiple events in our model. In other words, if a student entered a classification, exited it promptly, and then re-entered it later in the semester, we recorded this re-entry in our analysis.

\section{Results}

The results from our event history model are presented in Table 1. Our four independent variables of interest are presented at the top of the table and the additional demographic controls used in our analysis are presented below. As described above, the "EXPLORE" alert status represents students performing below the course mean and the "ENGAGE" alert status represents students in the lowest quartile of performance.

\subsection{Entry Models}

Looking first at our entry models, we found that all four of our independent variables significantly predicted increased odds of entering the EXPLORE classification in the focal course. Specifically, students co-enrolled in a "difficult course" (IV1) in the same semester had 12 times greater odds of entering the EXPLORE classification $(p<0.001)$. When we compare majors (IV2), students in all of the disciplinary classifications had increased odds of entering an EXPLORE classification in the focal course when compared to students in hard applied disciplines. Students in soft pure had the highest increase in odds (4.87) and students in soft applied had the lowest increase in odds (1.75). In contrast, only soft applied students had a significant 
difference in odds when entering an ENGAGE classification in the focal course, as they were less likely than their peers in hard applied fields to do so $(0.62, \mathrm{p}<0.01)$.

Table 1. Odds Ratios of Predictors for Entering and Exiting EWS Classifications

\begin{tabular}{|c|c|c|c|c|}
\hline \multirow[b]{2}{*}{ Alert Status } & \multicolumn{2}{|l|}{ Entry } & \multicolumn{2}{|l|}{ Exit } \\
\hline & EXPLORE & ENGAGE & EXPLORE & ENGAGE \\
\hline IV1: Difficult Course & $13.1 * * *$ & $2.56^{* * *}$ & $5.17 * * *$ & $1.91 * * *$ \\
\hline \multicolumn{5}{|c|}{ IV2: Discipline of Major (vs. Hard Applied) } \\
\hline Soft Pure & $4.87 * * *$ & 0.91 & $0.19 * * *$ & $0.20 * * *$ \\
\hline Soft Applied & $1.75^{* *}$ & $0.62 * *$ & $0.56 * * *$ & $0.78 * *$ \\
\hline Hard Pure & $1.95 * *$ & 1.29 & 1.05 & 1.00 \\
\hline Undeclared & $2.48 * * *$ & 0.95 & 0.84 & $0.68 * * *$ \\
\hline \multicolumn{5}{|c|}{ IV3: Time Indicators for First Entry/Exit } \\
\hline Time & $2.15^{* * *}$ & 1.11 & $4.25 * * *$ & $4.53 * * *$ \\
\hline Time $^{2}$ & $0.95 * *$ & 0.99 & $0.88 * * *$ & $0.87 * * *$ \\
\hline Time $^{3}$ & $1.01^{*}$ & 1.00 & $1.01 * * *$ & $1.01 * * *$ \\
\hline \multicolumn{5}{|c|}{ IV4: Snowball Effect (Multiple Risk of Entry/Exit) } \\
\hline From 1 to 2 Courses & $2.02 * * *$ & $3.03 * * *$ & 0.75 & 0.93 \\
\hline From 2 to 3 Courses & $4.05^{* * *}$ & $7.61^{* * *}$ & N/A & 0.21 \\
\hline \multicolumn{5}{|l|}{ Gender (vs. Male) } \\
\hline Female & 1.09 & 0.91 & 0.97 & $0.69 * * *$ \\
\hline \multicolumn{5}{|l|}{ Race (vs. White) } \\
\hline Black & 1.21 & 1.08 & 0.80 & 1.15 \\
\hline Hispanic & $1.40^{*}$ & 1.21 & 1.24 & $0.63^{* * *}$ \\
\hline Asian & 1.17 & 0.94 & $1.22 * * *$ & 0.92 \\
\hline Multi & 1.11 & $1.34 * *$ & $1.95^{* * *}$ & $1.24 * * *$ \\
\hline Intl. (vs. U.S. Citizen) & $0.68 * * *$ & 1.00 & $0.79 * * *$ & $1.57 * * *$ \\
\hline First-Year Student & 1.04 & $0.88^{*}$ & $1.11^{*}$ & $1.10^{*}$ \\
\hline Math Placement Test Score & $0.98 * *$ & 1.00 & $0.97 * * *$ & $0.96^{* * *}$ \\
\hline
\end{tabular}

${ }^{*} \mathrm{p}<0.05 ; * * \mathrm{p}<0.01 ; * * * \mathrm{p}<0.001$

For the temporal independent variables (IV3), we found significant linear, squared, and cubed effects over time for the EXPLORE classifications only $(\mathrm{p}<0.001)$. These effects are illustrated in the graph in Figure 1 . The coefficients suggest that students experience increased risk from being in the EXPLORE classification in the focal course until shortly after the eleventh week of the course (a few weeks after midterm exams) when risk tapers off and actually decreases until the end of the course.

When experiencing academic difficulty in multiple courses (IV4), students who entered the EXPLORE classification in one course were twice as likely to enter the same classification in an additional course, and four times as likely to enter an EXPLORE classification in a third course when they experienced academic difficulty in two courses $(\mathrm{p}<0.001)$. The results for the ENGAGE classification were more extreme. Students experiencing difficulty in one course were over three times as likely to enter the ENGAGE classification in another course $(\mathrm{p}<0.001)$, and students with two classifications were over seven times as likely to enter the ENGAGE classification in another course. 


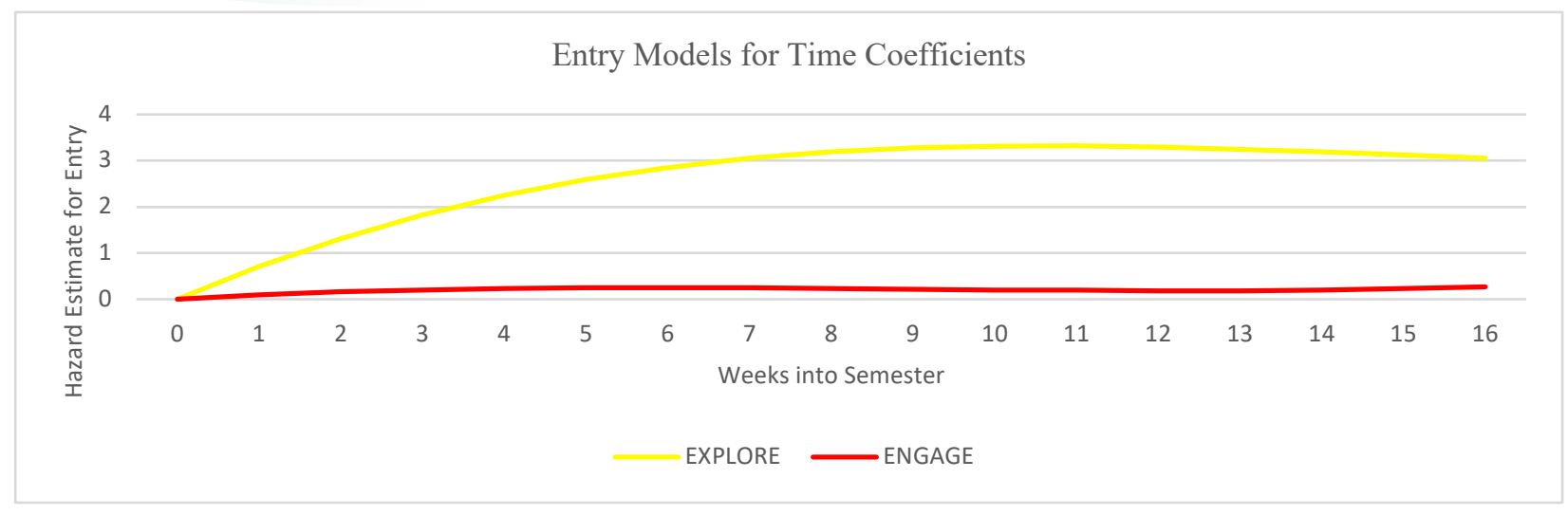

Figure 1. Temporal changes in hazard of entering classifications in focal course.

\subsection{Exit Models}

Turning to the exit models, we found significant results for three of our four independent variables. First, co-enrollment in a "difficult course" (IV1) in the same semester was a significant predictor of improved academic performance for both the EXPLORE and ENGAGE models in the focal course. For example, students co-enrolled in a "difficult course" who entered the EXPLORE classification in the focal course were over four times more likely to exit that classification for the focal course than their peers not co-enrolled in a "difficult course" $(\mathrm{p}<0.001)$. Similarly, students who entered the ENGAGE classification for the focal course and were co-enrolled in a "difficult course" were nearly twice as likely to exit that classification $(\mathrm{p}<0.001)$. In other words, students who were co-enrolled in "difficult courses" (other than the focal course) appear to be more likely to exit early warning classifications (once entered) for the focal course than their peers who were not co-enrolled in these difficult courses.Second, we also found significant differences across disciplines (IV2). For example, students majoring in soft pure fields were $81 \%$ less likely to exit the EXPLORE classification for the focal course $(p<0.001)$, and students majoring in soft applied fields were $44 \%$ less likely to do so $(p<0.001)$ when compared to their peers majoring in hard applied fields. We found similar results in the ENGAGE classification for the focal course, with soft pure students being $80 \%(\mathrm{p}<0.001)$, soft applied students being $22 \%(\mathrm{p}<0.01)$, and undeclared majors being $32 \%(\mathrm{p}<0.001)$ less likely to exit the ENGAGE classification than their hard applied peers.

Third, for the temporal independent variables (IV3), we found significant linear, squared, and cubed effects in both the EXPLORE and ENGAGE classifications for the focal course $(\mathrm{p}<0.001)$. These effects are also illustrated in Figure 2. These coefficients suggest that students experience increasing odds of exiting each of the EXPLORE and ENGAGE classifications for the focal course until around the eighth week of being in the classification. If students still remained in an EXPLORE or ENGAGE status for the focal course after that time, their odds of exiting remained stagnant until the end of the semester.

For the fourth independent variable (IV4), there were no significant differences among students' odds of recovery as the number of courses in which they experienced academic difficulty increased. This is most likely because among the few students who experienced academic difficulty in multiple courses, very few of those students improved academically as the course progressed. While this metric makes a good predictor of difficulty, it does not explain much about students' ability to recover (although it may, in its own way, be an excellent predictor of continued academic difficulty).

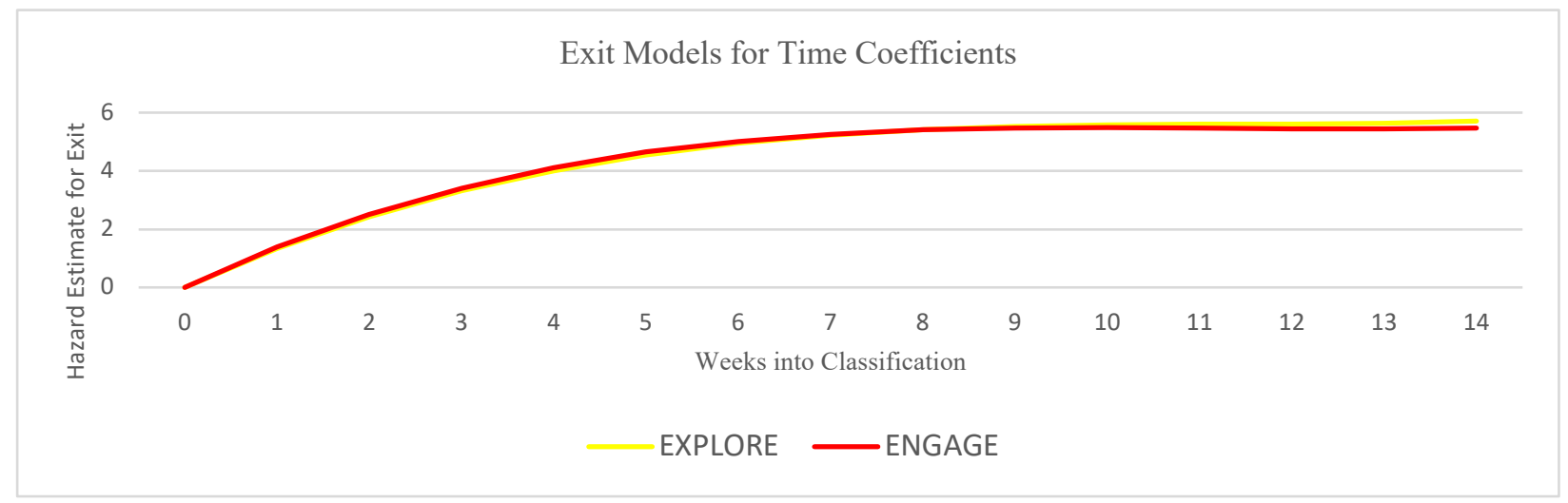

Figure 2. Temporal changes in hazard of exiting classifications in focal course. 


\subsection{Demographic Variables}

We include demographic variables that prior research has suggested are related to differences in academic performance in a STEM-focused course. Very few of these covariates related to demographics identify consistent trends across entry and exit of academic difficulty classifications for students. First year students were less likely to enter an ENGAGE classification (0.88; $\mathrm{p}<0.05$ ), and had higher odds of academic recovery than upperclassmen (EXPLORE=1.11; ENGAGE=1.10; $<<0.05$ ). For students with higher math placement exam scores, their odds of entering an EXPLORE classification decreased $(0.98 ; p<0.01)$ and their odds of recovering from an EXPLORE or ENGAGE classification increased ( 0.97 and $0.96 ; \mathrm{p}<0.001$ respectively).

\section{Discussion}

Our objective in this analysis was to conceptualize methods for exploring the influence of various enrollment and coenrollment factors on student performance in an introductory programming course. Our results identify metrics that help to unpack different aspects of curricular complexity, specifically instructional and structural complexity. We discuss each of these aspects separately below.

\subsection{Instructional Complexity}

Instructional complexity involves the inherent difficulty of coursework. Co-enrollment in a single "difficult course" may be the closest proxy available for estimating instructional complexity. In our study, co-enrollment in a "difficult course" (IV1), as identified by the percentage of students who experienced an EXPLORE or ENGAGE classification during the term in coenrolled courses (other than the focal course), was a significant predictor of increased odds of experiencing academic difficulty in the focal course. However, students co-enrolled in difficult courses were also more likely to exit the classification after entry in the focal course. This suggests that, while students who are simultaneously enrolled in these courses are at a greater risk of experiencing academic difficulty in the focal course, the process of experiencing academic difficulty may encourage students to develop study strategies that help them recover across their coursework; that is, in their difficult co-enrolled courses and in the focal course. This is consistent with our earlier research (Brown et al., 2017), which has shown that that different levels of academic difficulty, as indicated by the early warning system, are related to different effective strategies for academic recovery. In that earlier study, students experiencing moderate academic difficulty ("EXPLORE" alert status) benefited more from using tools that helped them plan their time, as compared to students experiencing severe academic difficulty ("ENGAGE" alert status). Students who have difficulty with self-regulation would, presumably, have trouble managing their time across their classes. Our findings also suggest that, while taking difficult courses increases a student's odds of experiencing academic difficulty in the focal course, the challenge posed by a difficult course is not insurmountable. In fact, recovering from academic difficulty in the focal course and in co-enrolled difficult courses and experiencing academic success in the focal course may help students develop essential study strategies. This is a potential strand of research that could capitalize on learning analytics data by examining how students perform in future semesters after experiencing academic difficulty.

The other component of instructional complexity that we examined involved accounting for experiences within disciplinary fields by including a covariate for a student's major program (IV2). This metric was perhaps less successful at identifying trends among changes in academic performance in the focal course, and may not accurately capture the disciplinary aspects of instructional complexity shared by fields within Biglan's (1973) typology. The focal course in this analysis is an introductory programming class intended for engineering majors. While, in some cases, students in hard applied fields (similar to the focal course) might have more experience with the kinds of instructional activities and assessments common to this course, very little about student majors explained differences in either their odds of entering an ENGAGE classification in the focal course or their odds of recovering from either classification for the focal course. Further research is needed to identify other aspects of instructional complexity, perhaps focused more on the actual instruction and assessment that occurs within the focal course, to explore other factors that may be related to academic difficulty or recovery.

\subsection{Structural Complexity}

In this study, we contribute to the growing body of research on structural complexity in university curricular design. For example, the temporal terms (IV3) we included in our model account for unfolding structural complexity in the design of courses. For the EXPLORE classification, student risk of entering this classification in the focal course increases until around the point of midterm exams, at which point students' odds actually decrease until around the end of the semester. This finding suggests that perhaps more attention should be placed on modelling student trajectories in the first eight to ten weeks. Presuming they have done well until this point, their odds of "slipping" into difficulty decrease substantially. This could be attributed to the distribution of grades throughout the semester (i.e., not many high-risk assessments are distributed between midterm and final examinations), or perhaps that students have adjusted to the expectations of the course, identifying strategies for how they can effectively succeed in the course throughout the rest of the semester. For exiting the EXPLORE and ENGAGE classifications, time is of the essence, given that we found the odds are greater of exiting the classification up until around the sixth week after entering the classification. After this point, the odds of exiting these classifications exponentially 
decrease. This finding suggests that there is a temporal window to academic recovery efforts. Both scholars and practitioners should consider the impact of time on their efforts to investigate academic performance. Courses where performance assessments are sequential and highly influential on final grade may result in conditions where students simply cannot recover after the window closes. For example, if students experience academic difficulty on the midterm examination and their next opportunity to recover is only the final examination, their odds of doing so appear quite small.

Our other measure of structural complexity, the number of courses in which a student is experiencing academic difficulty, is a better predictor of academic difficulty in the focal course than recovery. As students experience academic difficulty in multiple courses across the curriculum (IV4), we observe a potential "snowball effect" where students' odds of experiencing difficulty in other courses also increase. The exponential growth in the likelihood of entering either of the classifications in multiple courses (inclusive of the focal course) is troubling. The snowball effect may also have a temporal dimension, where increasing difficulty over time spreads across coursework. However, once entered, these students experiencing difficulty in multiple courses are no less likely to exit an EWS classification for the focal course than their peers experiencing difficulties in only one (co-enrolled difficult) course. Student difficulties might snowball, but the strategies that students engage in to recover may also work across their coursework.

This finding provides further evidence that, quite possibly, different metrics are needed that estimate difficulty and recovery in co-enrolled courses. After all, a predictor that effectively accounts for academic difficulty may be speaking to a different set of experiences and strategies than a proxy for academic recovery. Similarly, our findings reinforce the notion that different sets of predictors are needed to account for instructional versus structural complexity. While students were able (and likely) to recover from academic difficulty in the focal course when they were co-enrolled in a difficult course (a proxy for instructional complexity), they were no more likely to recover when they experienced challenges across the curriculum (a proxy for the complex structure of the curriculum). Further research is needed that teases apart instructional complexity from structural complexity in the curriculum. Additionally, researchers might consider how these factors play out over time. For example, are students better off taking difficult courses sequentially or concurrently? Are students who demonstrate the "snowball effect" in one semester at higher risk in future semesters?

\subsection{Implications for Academic Planning}

Understanding how instructional and structural complexity can facilitate academic planning practices is also an important future direction. We do not mean to suggest that applying insights from these analytic procedures alone could optimize the curriculum, but understanding how, when, and where students are likely to experience difficulty in the curriculum could help facilitate the provision of, and improve investment in, academic support resources. Given the increased emphasis on timely college completion in undergraduate higher education, academic planners might use these methods to identify the degree of difficulty in different course pathways. Administrators, departmental leads, and instructors can then make choices about the organization of the curriculum (by removing roadblocks), investing in resources that address instructional complexity (for difficult courses), and offering students more informed advising models about which courses to take in sequence and combination. Scalable approaches to curriculum design like these could ease a student's trajectory through undergraduate education.

\subsection{Implications for Early Warning and Course Recommender Systems}

Our initial analyses described above reinforces the need for academic analytics that consider interdependencies that emerge through the organization and enactment of the curriculum, especially for the development of early warning systems and course recommender systems. Early warning systems that do not incorporate data across all of the courses that students are taking along with the historical risk indicators that can be estimated from transcript data may be underestimating student risk of overall academic difficulty. Incorporating indicators that examine students' academic experiences during a semester across the curriculum could also improve EWS classification of student performance. For example, classification could (and perhaps should) reflect the difficulty of all of a student's coursework, as students taking a number of difficult courses simultaneously may need intervention and direction to academic support resources earlier in the semester (as illustrated by Figure 1). Specifically, co-enrollment information could be added to the underlying algorithms in the EWA to produce more studenttailored assessment of risk as the semester progresses. For institutions that use these systems to help connect students to learning resources like supplemental instruction, identifying risk early in the course and helping students connect to learner resources could prevent the kind of academic difficulty we outline above.

The methods we outline here could also be beneficial for building recommender systems like Degree Compass (Denley, 2014) to help students make informed decisions about the challenges they may encounter when selecting courses. Our work builds on similar efforts at building course recommender systems (Drachsler, Verbert, Santos, \& Manouselis, 2015) but extends that work by focusing on student performance throughout a semester rather than prediction models based on prior students' final grades or peer recommendations about courses. Designing a curriculum with little scheduling flexibility and/or recommending that students take courses in combination that have historically created curricular roadblocks may not be in the best interest of students or institutions. 


\subsection{Limitations}

This study is intended as a "proof of concept" to further the development of measures of instructional and structural complexity in undergraduate curriculum. It is necessarily limited in that it focuses on students drawn from one course at one highly competitive research university in North America. Very few students in this course and at this institution will fail a course. The metrics we propose above need to be replicated in institutional and classroom contexts with greater variation in academic performance. We hope that future researchers will take up the challenge we have laid out above to examine these measures in ways that explore multiple courses, multiple institutions, and a broad cross-section of post-secondary systems across nation states. Future work is needed to determine the extent to which these results are replicable across contexts.

\subsection{Future Directions}

Our results point to several promising future directions for learning analytics work aimed at improving student success across a curriculum, rather than only in individual courses. We invite our colleagues in other post-secondary institutions to replicate this work with courses on their own campuses, especially those courses considered to be "gateway" courses in a major, to identify how common these significant relationships might be. We have created parsimonious metrics in order to facilitate reproduction of this analysis, even in the absence of EWS data.

Our hope is that other researchers and practitioners will take up these methodological approaches in combination with the curriculum analytic approaches described above and innovative course recommender systems (e.g., Denley, 2014; Drachsler et al., 2015) to rethink how we can best support student academic planning.

Translating this work to scale and conceptualizing co-enrollment could support the re-organization of general education by helping institutions of higher education reflect on the organization of the system-wide curriculum. Examining co-enrollment risk factors across institutions and among national systems could help researchers identify issues that are local and perhaps ingrained in the system. Local risk factors could be addressed through the better allocation of help-seeking and academic support resources for high risk courses and organization of academic major programs to avoid course combinations that increase student risk of experiencing academic difficulty. When these problems are endemic to the system, examining coenrollment could supplement pedagogical knowledge as faculty plan their courses, develop major programs, and participate in academic planning.

\section{Declaration of Conflicting Interest}

The author(s) declared no potential conflicts of interest with respect to the research, authorship, and/or publication of this article.

\section{Funding}

The author(s) declared no financial support for the research, authorship, and/or publication of this article.

\section{References}

Adelman, C. (2006). The toolbox revisited: Paths to degree completion from high school through college. Washington, DC: U.S. Department of Education.

Aldrich, P. R. (2015). The curriculum prerequisite network: Modeling the curriculum as a complex system. Biochemistry and Molecular Biology Education, 43(3), 168-180. http://dx.doi.org/10.1002/bmb.20861

Attewell, P., Heil, S., \& Reisel, L. (2012). What is academic momentum? And does it matter? Educational Evaluation and Policy Analysis, 34(1), 27-44. http://dx.doi.org/10.3102/0162373711421958

Biglan, A. (1973). Relationships between subject matter characteristics and the structure and output of university departments. Journal of Applied Psychology, 57(3), 204. http://dx.doi.org/10.1037/h0034699

Braxton, J. M., \& Hargens, L. L. (1996). Variation among academic disciplines: Analytical frameworks and research. Higher Education, 11, 1-46.

Brown, M., DeMonbrun, R. M., Lonn, S., Aguilar, S., \& Teasley, S. D. (2016). What and when: The role of course type and timing in students' academic performance. Proceedings of the $6^{\text {th }}$ International Conference on Learning Analytics and Knowledge (LAK '16), 25-29 April 2016, Edinburgh, UK (pp. 459-468). New York: ACM. http://dx.doi.org/10.1145/2883851.2883907

Brown, M., DeMonbrun, R. M., \& Teasley, S. D. (2017). Don't call it a comeback: Academic recovery and the timing of educational technology adoption. Proceedings of the $7^{\text {th }}$ International Conference on Learning Analytics and Knowledge (LAK '17), 13-17 March 2017, Vancouver, BC, Canada (pp. 489-493). New York: ACM. http://dx.doi.org/10.1145/3027385.3027393

Brown, M., DeMonbrun, R. M., \& Teasley, S. D. (2018). Conceptualizing co-enrollment: Accounting for student experiences across the curriculum. Proceedings of the $8^{\text {th }}$ International Conference on Learning Analytics and Knowledge (LAK '18), 5-9 March 2018, Sydney, NSW, Australia (pp. 305-309). New York: ACM. 
http://dx.doi.org/10.1145/3170358.3170366

Calcagno, J. C., Crosta, P., Bailey, T., \& Jenkins, D. (2006). Stepping stones to a degree: The impact of enrollment pathways and milestones on older community college student outcomes (CCRC Brief No. 32). New York: Community College

Research Center, Teachers College, Columbia University. http://dx.doi.org/10.1007/s11162-007-9053-8

Chambliss, D., \& Takacs, C. G. (2014). How college works. Harvard University Press.

Dawson, S., \& Hubball, H. (2014). Curriculum analytics: Application of social network analysis for improving strategic curriculum decision-making in a research-intensive university. Teaching and Learning Inquiry: The ISSOTL Journal, 2(2), 59-74. http://dx.do.org/10.2979/teachlearninqu.2.2.59

Drachsler, H., Verbert, K., Santos, O., \& Manouselis, N. (2015) Panorama of recommender systems to support learning. In F. Ricci, L. Rokach, \& B. Shapira (Eds.), Recommender systems handbook (pp. 421-451). Boston, MA: Springer. http://dx.doi.org/10.1007/978-1-4899-7637-6 12

DeMonbrun, R. M., Brown, M., \& Teasley, S. D. (2018). The snowball effect: Exploring the influence of changes in academic performance in co-enrolled courses. Proceedings of the $125^{\text {th }}$ Association for the Study of Engineering Education Conference \& Exposition (ASEE 2018), 24-27 June 2018, Salt Lake City, UT, USA. Paper ID \#21935.

Denley, T. (2014). How predictive analytics and choice architecture can improve student success. Research \& Practice in Assessment, 9, 61-69.

Eccles, J. S., \& Wigfield, A. (2002). Motivational beliefs, values, and goals. Annual Review of Psychology, 53(1), 109-132.

Feng, Y., Fiorini, S., Shepard, L., \& Groth, D. (2017). The effect of grades in STEM courses on retention. Proceedings of the $13^{\text {th }}$ Annual National Symposium on Student Retention, 6-9 November 2017. Destin, FL, USA (pp. 416-427). Consortium for Student Retention Data Exchange/University of Oklahoma.

Heileman, G. L., Hickman, M., Slim, A., \& Abdallah, C. T. (2017). Characterizing the complexity of curricular patterns in engineering programs. Paper presented at 2017 ASEE Annual Conference \& Exposition, Columbus, Ohio. https://peer.asee.org/28029

Hodara, M., \& Rodríguez, O. (2013). Tracking student progression through the core curriculum: CCRC analytics. New York: Community College Research Center, Teachers College, Columbia University.

Ishitani, T. T. (2006). Studying attrition and degree completion behavior among first-generation college students in the United States. Journal of Higher Education, 77(5), 861-885. http://dx.doi.org/10.1080/00221546.2006.11778947.

Knight, S., Wise, A. F., \& Chen, B. (2017). Time for change: Why learning analytics needs temporal analysis. Journal of Learning Analytics, 4(3), 7-17. http://dx.doi.org/10.18608/jla.2017.43.2

Laird, T. F. N., \& Garver, A. K. (2010). The effect of teaching general education courses on deep approaches to learning: How disciplinary context matters. Research in Higher Education, 51(3), 248-265. http://dx.doi.org/10.1007/s11162009-9154-7

Lattuca, L. R., \& Stark, J. S. (2011). Shaping the college curriculum: Academic plans in context. Hoboken, NJ: John Wiley $\&$ Sons.

Lightfoot, J. M. (2010). A graph-theoretic approach to improved curriculum structure and assessment placement. Communications of the IIMA, 10(2), 5 .

Lonn, S., \& Teasley, S. D. (2014). Student explorer: A tool for supporting academic advising at scale. Proceedings of the $1^{\text {st }}$ ACM Conference on Learning @ Scale (L@S 2014), 4-5 March 2014, Atlanta, Georgia, USA (pp. 175-176). New York: ACM. http://dx.doi.org/10.1145/2556325.2567867

Martin, A. J., Wilson, R., Liem, G. A. D., \& Ginns, P. (2013). Academic momentum at university/college: Exploring the roles of prior learning, life experience, and ongoing performance in academic achievement across time. Journal of Higher Education, 84(5), 640-674. http://dx.doi.org/10.1080/00221546.2013.11777304

Mayhew, M. J., Pascarella, E. T., Bowman, N. A., Rockenbach, A. N., Terenzini, P. T., Seifert, T. A., \& Wolniak, G. C. (2016). How college affects students: 21 st century evidence that higher education works (Vol. 3). Hoboken, NJ: John Wiley \& Sons.

Mahzoon, M. J., Maher, M. L., Eltayeby, O., Dou, W., \& Grace, K. (2018). A sequence data model for analyzing temporal patterns of student data. Journal of Learning Analytics, 5(1), 55-74. http://dx.doi.org/10.18608/jla.2018.51.5

Macfadyen, L. P., \& Dawson, S. (2010). Mining LMS data to develop an "early warning system" for educators: A proof of concept. Computers \& Education, 54(2), 588-599. http://dx.doi.org/10.1016/j.compedu.2009.09.008

Meghanathan, N. (2017). Curriculum network graph: Relative contribution of courses. International Journal of Network Science, 1(3), 223-247. http://dx.doi.org/10.1504/IJNS.2017.083580

Nam, S., Lonn, S., Brown, T., Davis, C., \& Koch, D. (2014). Customized course advising: Investigating engineering student success with incoming profiles and patterns of concurrent course enrollment. Proceedings of the $4^{\text {th }}$ International Conference on Learning Analytics and Knowledge (LAK '14), 24-28 March 2014, Indianapolis, IN, USA (pp. 16-25). New York: ACM. http://dx.doi.org/10.1145/2567574.2567589

Nespor, J. (2007). Curriculum charts and time in undergraduate education. British Journal of Sociology of Education, 28(6), 753-766. http://dx.doi.org/10.1080/01425690701610092 
Pascarella, E. T., \& Terenzini, P. T. (2005). How college affects students. San Francisco, CA: Jossey-Bass.

Perez, T., Cromley, J. G., \& Kaplan, A. (2014). The role of identity development, values, and costs in college STEM retention. Journal of Educational Psychology, 106(1), 315. http://dx.doi.org/10.1037/a0034027

Phadke, A. S., \& Kulkarni, S. S. (2018). Use of network model for analysis of curriculum and its mapping to program outcomes. Journal of Engineering Education Transformations, 31(3), 30-34.

http://dx.doi.org/10.16920/jeet/2018/v31i3/120752

Seymour, E., \& Hewitt, N. M. (1997). Talking about leaving. Boulder, CO: Westview Press.

Slim, A. (2016). Curricular analytics in higher education (Doctoral dissertation, University of New Mexico).

Slim, A., Heileman, G. L., Kozlick, J., \& Abdallah, C. T. (2014a). Employing Markov networks on curriculum graphs to predict student performance. Proceedings of the 13th International Conference on Machine Learning and Applications (ICMLA 2014), 3-5 December 2014, Detroit, MI, USA (pp. 415-418). IEEE. http://dx.doi.org/10.1109/ICMLA.2014.74

Slim, A., Heileman, G. L., Kozlick, J., \& Abdallah, C. T. (2014b). Predicting student success based on prior performance. Proceedings of the IEEE Symposium on Computational Intelligence and Data Mining (CIDM 2014), 9-12 December 2014, Orlando, FL, USA (pp. 410-415). IEEE. http://dx.doi.org/10.1109/CIDM.2014.7008697

Slim, A., Kozlick, J., Heileman, G. L., Wigdahl, J., \& Abdallah, C. T. (2014c). Network analysis of university courses. Proceedings of the $23^{\text {rd }}$ International Conference on World Wide Web (WWW '14), 7-11 April 2014, Seoul, Republic of Korea (pp. 713-718). New York: ACM. http://dx.doi.org/10.1145/2567948.2579360

Slim, A., Kozlick, J., Heileman, G. L., \& Abdallah, C. T. (2014d). The complexity of university curricula according to course cruciality. Proceedings of the $8^{\text {th }}$ International Conference on Complex, Intelligent and Software Intensive Systems (CISIS 2014), 2-4 July 2014, Birmingham UK (pp. 242-248). IEEE. http://dx.doi.org/10.1109/CISIS.2014.34

Tinto, V. (1997). Classrooms as communities: Exploring the educational character of student persistence. Journal of Higher Education, 68(6), 599-623. http://dx.doi.org/10.1080/00221546.1997.11779003

Trowler, P., \& Cooper, A. (2002). Teaching and learning regimes: Implicit theories and recurrent practices in the enhancement of teaching and learning through educational development programmes. Higher Education Research and Development, 21(3), 221-240. http://dx.doi.org/10.1080/0729436022000020742

Villano, R., Harrison, S., Lynch, G., \& Chen, G. (2018, March 3). Linking early alert systems and student retention: A survival analysis approach. Higher Education, 1-18. http://dx.doi.org/10.1007/s10734-018-0249-y

Wang, X. (2016). Course-taking patterns of community college students beginning in STEM: Using data mining techniques to reveal viable STEM transfer pathways. Research in Higher Education, 57(5), 544-569. http://dx.doi.org/10.1007/s11162-015-9397-4

Wang, Y., Liu, X., \& Chen, Y. (2017). Analyzing cross-college course enrollments via contextual graph mining. PloS One, 12(11), e0188577. http://dx.doi.org/10.1371/journal.pone.0188577

Willcox, K. E., \& Huang, L. (2017). Network models for mapping educational data. Design Science, 3. http://dx.doi.org/10.1017/dsj.2017.18

Wigdahl, J., Heileman, G. L., Slim, A., \& Abdallah, C. T. (2014). Curricular efficiency: What role does it play in student success? Proceedings of the $121^{\text {st }}$ Annual Conference \& Exposition of the American Society for Engineering Education (ASEE 2014), 15-18 June 2018, Indianapolis, IN, USA. IEEE. https://peer.asee.org/20235 